\title{
TEKNOLOGI TERAPAN UNTUK INDUSTRI RUMAH TANGGA ANEKA ABON
}

\author{
Fitri Marisa ${ }^{1}$, Chauliah Fatma Putri ${ }^{2}$ \\ ${ }^{1}$ Universitas Widyagama Malang \\ E-Mail : fitrimarisa@widyagama.ac.id
}

\begin{abstract}
Abstrak
Industri Rumah Tangga (IRT) merupakan bidang usaha kecil yang harus didukung karena keberadaan menjadi salah satu penyumbang inkam perkapita penduduk. IRT aneka abon menjadi salah satu dari sekian banyak IRT di kecamatan Karangploso kabupaten Malang yang berpotensi namun membutuhkan bantuan baik pihak lembaga maupun pemerintah. Terdapat tiga permasalahan pada IRT aneka Abon antara lain: 1) memiliki peralatan produksi yang kurang memadai khususnya alat peniris minyak sehingga menyebabkan proses produksi tidak efisien dan hasil penirisan kurang sempurna, 2) dari segi manajemen, yaitu pencatatan keuangan yang masih manual dan tidak terstruktur sehingga sulit mengetahui omzet, estimasi produksi, laba, dan rugi, dan 3) dari segi pemasaran, yaitu kurang luasnya pemasaran sehingga peningkatan omzet tidka sesuai target. Maka tiga program yang akan dilaksanakan adalah 1) merancang dan membuat alat peniris minyak (spinner) dengan kapasitas lebih besar dan desain mesin yang sistematis, 2) membangun dan menerapkan aplikasi keuangan berbasis komputer untuk menganalisis keuangan, 3) membangun dan menerapkan website untuk meningkatkan pemasaran dan memudahkan proses penjualan. Pada tiga program ini telah menghasilkan : rangkatan alat peniris minyak (spinner), aplikasi keuangan berbasis komputer, ECommerce aneka abon.
\end{abstract}

Kata kunci: Industri Rumah Tangga, Spninner, Aplikasi keuangan, E-Commerce.

\section{PENDAHULUAN}

Dengan banyaknya hasil ternak ayam, lele, dan kelinci maka masyarakat Karangploso kabupaten Malang kreatif mengolah dari bahan baku tersebut menjadi produk olahan mulai dari lalapan, sate hingga bentuk olahan Aneka Abon Bebas Pengawet. Keberadaan Aneka Abon menjadi salah satu variasi produk olahan berbahan dasar daging ayam, lele, dan kelinci dapat memperbanyak jumlah pemanfaatan hasil peternakan sebagai produk olahan, dan tentunya menghasilkan keuntungan yang lebih besar daripada hanya dijual dalam bentuk lalapan atau sate. IRT aneka abon menjadi salah satu dari sekian banyak IRT di kecamatan Karangploso kabupaten Malang yang berpotensi namun membutuhkan bantuan baik pihak lembaga maupun pemerintah. IRT Abon Bunda dan IRT Abon Queely adalah 2 sekian banyak IRT berpotensi yang menjadi mitra dalam program ini.

Berdasarkan tiga permasalahan yang telah dirumuskan maka telah dilakukan tiga upaya perancanagn dan penerapan teknologi untuk menyelesaikan permasalahan yang ada pada mitra yaitu: 1) merancang dan membuat alat peniris minyak (spinner) dengan kapasitas lebih besar dan desain mesin yang sistematis, 2) membangun dan menerapkan aplikasi keuangan berbasis komputer untuk menganalisis keuangan, 3) membangun dan menerapkan website untuk meningkatkan pemasaran dan memudahkan proses penjualan.

\section{SOLUSI DAN TARGET}

Bardasarkan masalah yang telah dikemukakan, maka dirumuskan solusi untuk menyelesaikan permasalahan:

1 Merancang alat spinner yang berkapastias besar dan dapat meniriskan minyak secara maksimal.

2 Merancang aplikasi keuangan IRT yang dapat mengetahui laba rugi dan estimasi produksi.

3 Merancan website pemasaran produk IRT untuk promosi dan penjualan skala yang lebih luas.

Semantara target luaran yang diharapkan adalah sebagai berikut:

1. Menghasilkan alat spinner yang berteknologi untuk meniriskan minyak yang lebih optimal. 
2. Menghasilkan aplikasi sistem pengelolaan keuangan IRT yang baik sehingga semua transaksi dapat tercatat dan ternalisis dengan baik melalui pembuatan aplikasi keuangan sederhana.

3. Menghasilkan aplikasi web pemasaran produk yang terhubung dengan facebook, melalui pembuatan web, pelatihan, dan pendampingan.

\section{METODE KEGIATAN}

\section{Pada aspek Pengembangan alat:}

1. Membuat desain peniris minyak dengan posisi mesin sistematis dan tidak mengganggu bekerjanya alat.

2. Membuata alat sesuai dengan desain dengan posisi dinamo samping.

3. Menperagakan alat agar mitra memahami dan dapat mengoperasikan alat dengan benar.

4. Pelatihan dan pendampingan pemakaian alat.

\section{Pada Aspek Manajemen}

Pasa segi manajemen fokus pada membangun aplikasi keuangan UKM sehingga mitra dapat menganalisis omzet, perencanaan produksi dan pengembangan usaha., dimana dilakukan dalam tahap-tahap berikut:

1. Observasi dan analisis kebutuhan.

2. Merancang aplikasi keuangan sesuai kebutuhan.

3. Menerapkan aplikasi kpada mitra.

4. Pelatihan pengoperasian aplikasi dan pendampingan.

\section{Pada aspek pemasaran:}

1. Melakukan survei dan analisis kebutuhan konten IRT oleh Tim.

2. Mendesain website profil dan pemasaran IRT.

3. Mengimplementasikan website dengan mendaftarkan domain ke jaringan internet.

4. Pelatihan dan pendampingan pengoperasian website kepada Mitra.

\section{HASIL DAN PEMBAHASAN}

Hasil program kemitraan masyarakat ini terdiri dari tiga luaran yaitu:

1. Rangkaian alat peniris minyak (spinner) berkapasitas $5 \mathrm{~kg}$ dengan posisi dinamo di samping sehingga dapat mengefisienkan proses produksi.

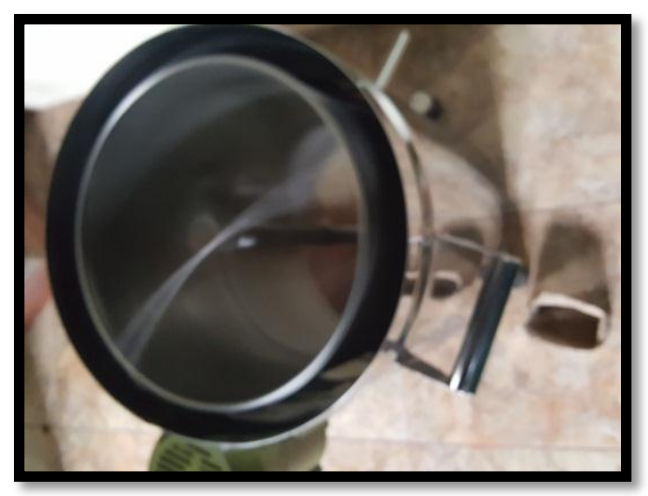

Gambar 1: Alat spinner

2. Hasil kedua adalah aplikasi keuangan IRT Aneka Abon.

Aplikasi keuangan berbasis kemputer sangat membantu mitra dalam menganalisis keuangannya, mengetahui laba, rugi dan omzet usaha.

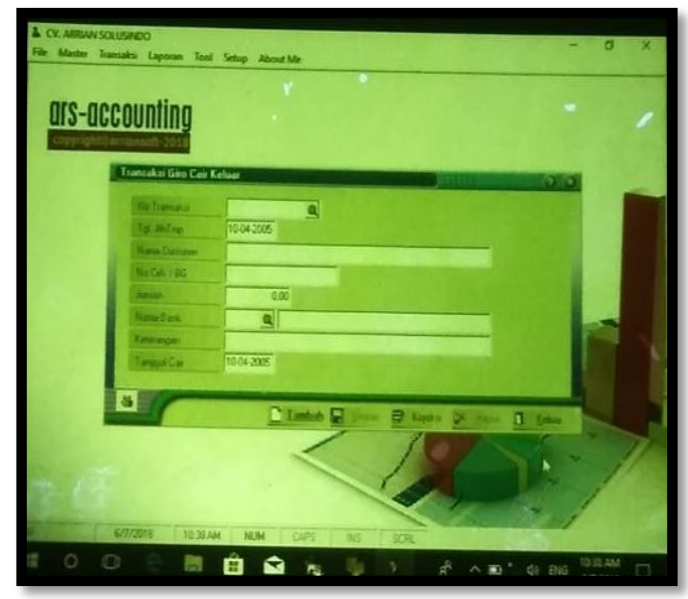

Gambar 2: Aplikasi keuangan

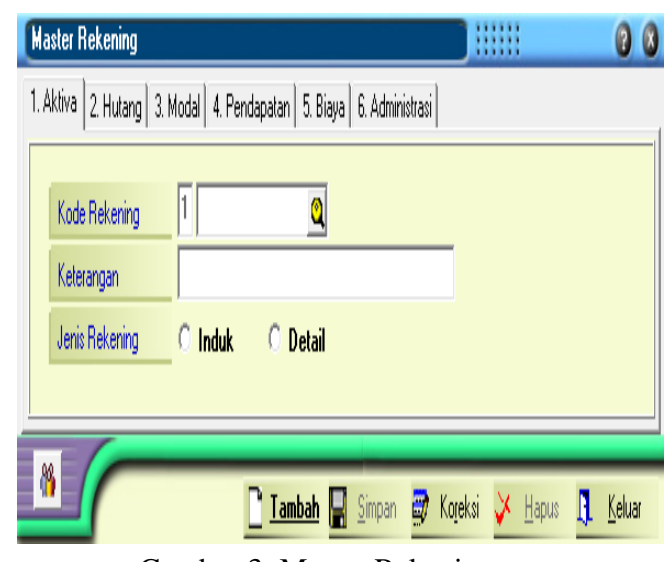

Gambar 3: Master Rekening 
Pada Gambar 3 menunjukkan form master rekening yang berfungsi untuk pendaftaran jenis rekenik transaksi,

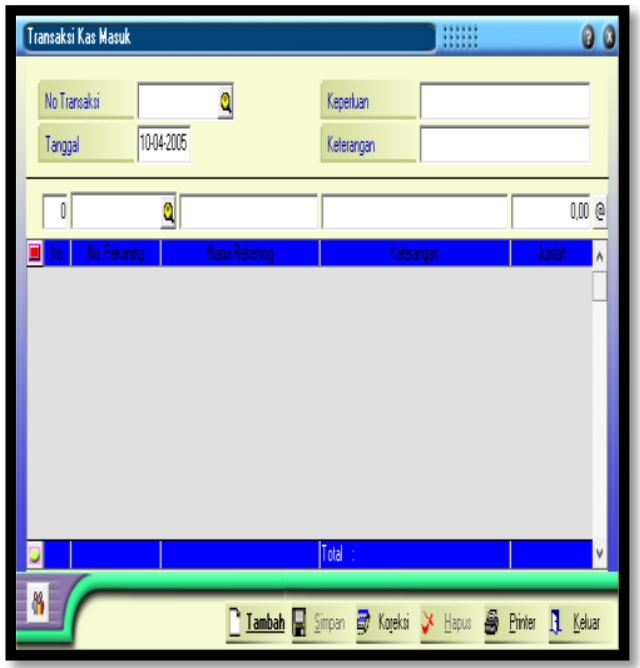

Gambar 4: Transaksi kas masuk

Pada Gambar 4 menunjukkan transaksi kas masuk yang berfungsi untuk mengisikan seluruh transaksi kas masuk.

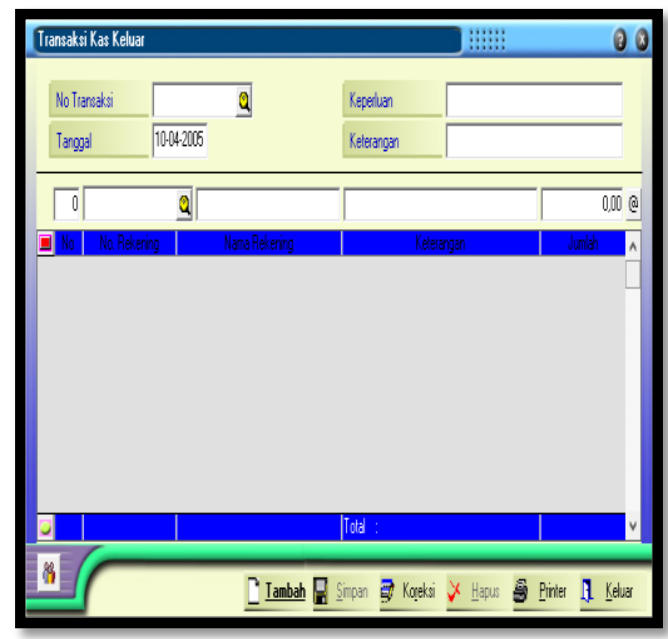

Gambar 5: Transaksi kas keluar

Pada gambar 5 menunjukkan transaksi kas keluar yang berfungsi untuk mengisikan seluruh transaksi kas keluar.

3. Hasil ketiga adalah website E-Commerce aneka abon.

Dengan website E-Commerce maka mitra lebih memperluas pasaran dan memudahkan pembeli untuk membei barang.

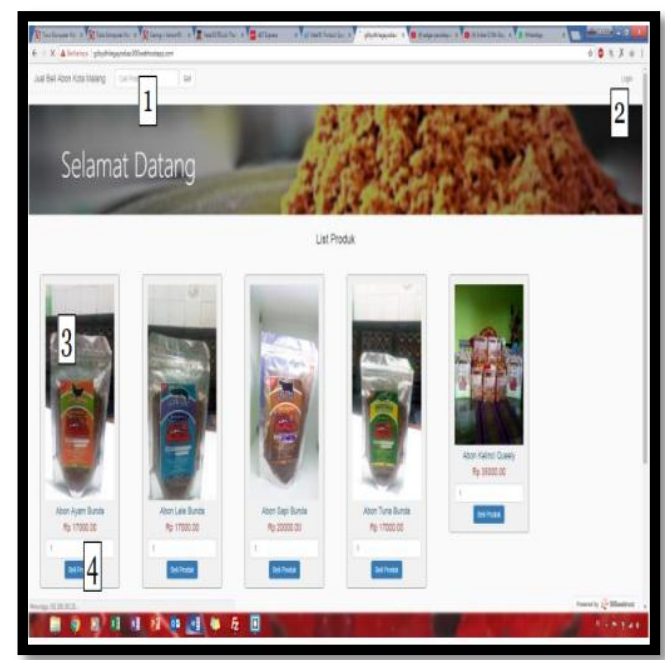

Gambar 6: E-Commerce aneka abon

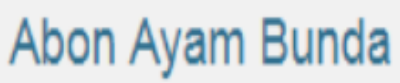
Rp 17000.00

1

\section{Beli Produk}

Gambar 7: format pemesanan

Pada gambar 7 menunjukkan format pembelian produk yang berisi harga dan jumlah pemesanan.

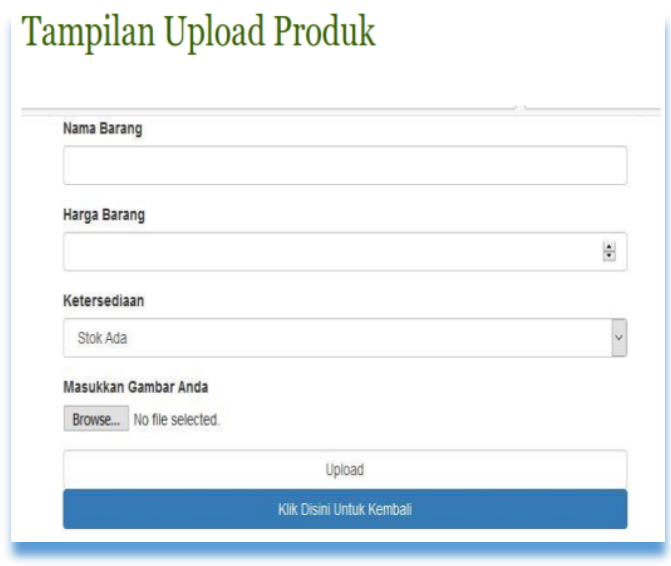

Gambar 8: Pampilan upload produk.

Pada gambar 8 digunakan oleh admini untuk mengupload produk pada server dan nanti akan dapat dilihat dalam akun pelanggan. 


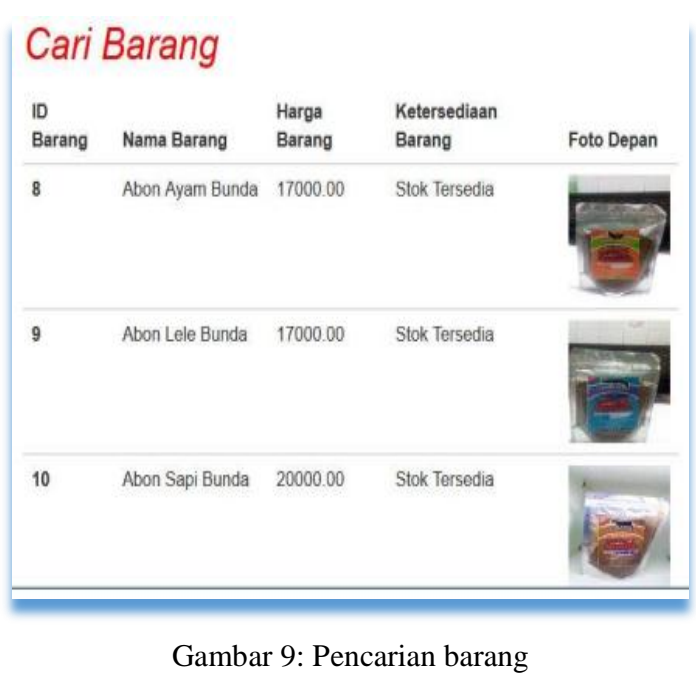

Pada gambar 9 terdapat menu pencarian barang yang dapat dilakukan oleh pembeli maupun admin.

\section{Hasil Perubahan Efektifitas dan efisiensi produksi.}

Berikut disajikan data perkembangan perubahan jumlah produksi dari alat yang lama dengan alaat yang baru (dalam hal ini spinner. Disajikan ilustrasi dalam 5 kali produksi dimana yang sebelumnya dalam satu kali produksi beban yang dapat ditanggung spinner sebesar $2 \mathrm{~kg}$, setalah menggunakan alat yang baru menjadi $5 \mathrm{~kg}$ setiap produksi. Dengan demikian dapat disimpulan dengan spinner yang baru proses produksi menjadi lebih efektif dan efisien.

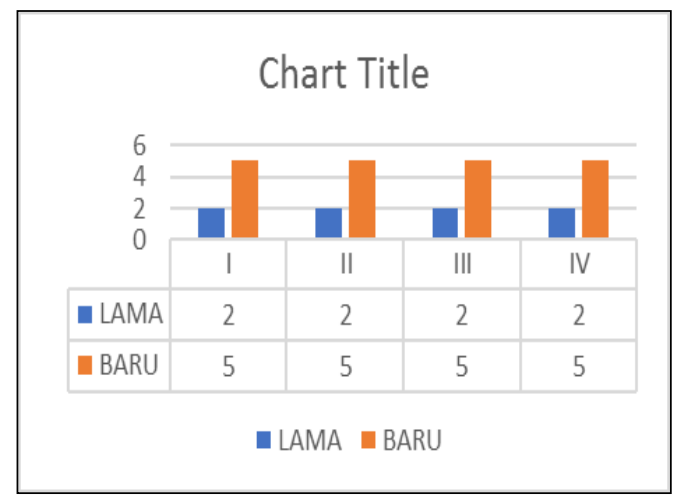

Gambar 10: Grafik perbandingan proses produksi dari alat lama dengan alat yang baru.

\section{KESIMPULAN DAN SARAN.}

\section{KESIMPULAN}

1. IRT aneka abon memiliki alat peniris minyak dengan kapasitas yang memadai akan sangat membantu dalam segi efektifitas dan efisiensi produksi.
2. Keuangan yang dikelola dengan baik dan menggukana sistem informasi keuangan maka akan sangat membantu IRT dalam menganalisis usahanya.

3. Dengan diterapkannya E-Commerce maka akan memperluas promosi IRT agar lebih luar dikenal masyarakat dan sekaligus memudahkan transaksi penjualan.

\section{SARAN}

1. Persaingan usaha dalam skup usaha kecil semakin besar untuk itu diperlukan evaluasi yang terus menerus bagi UKM dan dibantu pihak-pihak yang terkait.

2. Kreatifitas UKM tidak diimbangi dengan bekal kemampuan marketing yang cukup sehingga diperlukan pelatihan-pelatihan yang berhubungan dengan pemasaran agar produk kreatif yang dihasilkan akan dapat lebi banyak dikenal masyarakat secara luas.

\section{REFERENSI}

Baroto, T. "Perencanaan dan Pengendalian Produksi”. 2002. Ghalia, Jakarta.

Pugra, I W. "Buku Ajar Teknik Pengolahan Makanan 3". 2005. Denpasar: Politeknik Negeri Bali

Ramadan, Sudiharto, Suyono. "Rancang Bangun Abon Penirin Minyak pada Abon dan Kripik Kentang dengan Menggunakan Inverter”. 2016. Proseding seminar nasional multidisiplin ilmu dan Call for paper. PENS. https://www.pens.ac.id/uploadta/downloadmk.p hp?id=1643.

Subagyo, P. "Manajemen Operasi". 2000. BPFE. Jogjakarta.

Wasisto, Purnama, Anggoro. "Perancangan Mesin Peniris Untuk Aneka Makanan Ringan Hasil Gorengan”. 2016. Proseding seminar nasional multidisiplin ilmu dan Call for paper. Unisbank. https://www.google.co.id/url?sa=t\&rct=j\&q=\& esrc $=$ s\&source $=$ web $\& \mathrm{~cd}=2 \& \mathrm{cad}=\mathrm{rja} \& u a c t=8 \&$ ved=0ahUKEwi7pfL3h7jTAhUEpo8KHbQ3B BwQFggpMAE\&url=https\%3A\%2F\%2Fwww. unisbank.ac.id\%2Fojs\%2Findex.php\%2Fsendi u\%2Farticle\%2Fdownload\%2F4198\%2F1212\& usg=AFQjCNHTEOEWEc4iKwxT6oe68jbMRpX2g 
